Original Research Article

\title{
Antioxidant activity of ethanolic extract of Calotropis procera root in wistar rats
}

\author{
Kunjumon Dayana ${ }^{1}$, Megaravalli R. Manasa ${ }^{2 *}$
}

${ }^{1}$ Department of Pharmacology, Pushpagiri Institute of Medical Sciences and Research Centre, Thiruvalla, Kerala, India ${ }^{2}$ Department of Pharmacology, Karwar Institute of Medical Sciences, Karwar, Karnataka, India

Received: 27 September 2018 Accepted: 02 October 2018

\section{*Correspondence to:}

Dr. Megaravalli R. Manasa, Email: dr.manasamr@ gmail.com

Copyright: (C) the author(s), publisher and licensee Medip Academy. This is an openaccess article distributed under the terms of the Creative Commons Attribution NonCommercial License, which permits unrestricted noncommercial use, distribution, and reproduction in any medium, provided the original work is properly cited.

\begin{abstract}
Background: Free radicals generated as by-products of metabolism can cause damage to lipids, proteins and DNA. They are scavenged by endogenous antioxidant mechanisms. But when these mechanisms are overwhelmed, free radicals can cause toxicity. There is a need to identify new antioxidant compounds. Hence the current study was undertaken to assess the antioxidant activity of ethanolic extract of Calotropis procera roots in Wistar rats.

Methods: Wistar rats were divided into 4 groups. Group 1 (control) were administered vehicle. Group 2 received DMBA (30mg/kg BW, single dose) intraperitoneally on day 5. Group 3 was pre-treated with Calotropis procera root extract $(500 \mathrm{mg} / \mathrm{kg} \mathrm{BW})$ orally for 5 days. On day 5 , they were given DMBA injection $2 \mathrm{hrs}$ after the extract. Group 4 rats received only root extract for 5 days. All rats were sacrificed on day 6 and samples were analysed for TBARS, conjugated dienes and antioxidant enzymes (SOD, CAT, GPx) levels.

Results: The levels of TBARS, conjugated dienes were significantly increased, and antioxidant enzymes were decreased in group 2 both in plasma and erythrocytes. Pretreatment with $C$. procera root extract (group 3 ) has normalized the TBARS and conjugated dienes levels in plasma but in erythrocytes, TBARS levels are elevated. GPx activity was significantly decreased in both plasma and erythrocytes and SOD activity was decreased in erythrocytes. CAT activity was comparable to control group. Group 4 rats showed TBARS, conjugated dienes and antioxidant enzymes levels comparable to control.
\end{abstract}

Conclusions: The present study establishes that Calotropis procera root extract has antioxidant activity in wistar rats.

Keywords: Antioxidant, Calotropis procera, Free radicals, Wistar rats

\section{INTRODUCTION}

Free radicals are short lived and highly reactive molecules. They are generated continuously as a result of normal metabolism. ${ }^{1}$ They are exploited by immune system for lysing micro-organisms. But when produced in excess quantity, they become toxic. ${ }^{2}$ The striking feature of free radicals is lipid peroxidation leading to tissue damage and cell death. ${ }^{3}$ They are involved in the pathogenesis of various degenerative disorders, cancer, aging, Alzheimer's disease, diabetes, etc. ${ }^{4,5}$ The free radicals are scavenged by antioxidant defense mechanisms. The enzymatic antioxidants (SOD, CAT, GPx) and non-enzymatic antioxidants (Vitamin C, E and GSH) protect the tissues from free radical toxicity. ${ }^{6}$

Many medicinal plants are reported to exhibit antioxidant property with minimal side effects. Calotropis procera $(C$. procera) has been used in traditional medicine as antioxidant. ${ }^{7}$ It belongs to Asclepiadaceae family. ${ }^{8}$ It is known to have various activities like immunomodulatory, anti-inflammatory, antidiabetic, antiulcer, anticancer, analgesic, etc. $C$. procera contains triterpinoids, calotropin, calotoxin, cardiac glycosides, calactin. ${ }^{9-15} 7,12-$ Dimethylbenz[a]anthracene (DMBA), a commonly used experimental cancer inducing agent, is an incomplete carcinogen. It has to be activated metabolically. ${ }^{16}$ During 
this process, there is generation of excess free radicals which can damage DNA, lipids as well as proteins both structurally and functionally. ${ }^{17}$ Estimation of lipid peroxides and antioxidants levels in circulation are dependable parameters for antioxidant potential as these indicate their bioavailability and utilization. ${ }^{18}$ The assay of TBARS levels and antioxidant enzymes activities is a consistent method for screening potential antioxidant compounds. The current study was planned to evaluate the antioxidant activity of ethanolic extract of Calotropis procera roots in wistar rats.

\section{METHODS}

\section{Chemicals}

Heparin, thiobarbituric acid (TBA), trichloroacetic acid, 2, 4 dinitrophenyl hydrazine (DNPH), 5,5' dithiobis (2 - nitro benzoic acid) (DTNB), nitroblue tetrazolium (NBT), phenazine methosulphate (PMS), cysteine hydrochloride were purchased from Hi-media laboratories, Mumbai, India. 7,12-Dimethylbenz[a]anthracene (DMBA), biochemical compounds - reduced glutathione (GSH), reduced nicotinamide adenine dinucleotide (NADH) were bought from sigma Aldrich Pvt Ltd, Bengaluru, India. All chemicals were of analytical grade.

\section{Preparation of ethanol extract of Calotropis procera root}

The dried roots of $C$. procera and absolute alcohol were combined in a soxhlet apparatus for 7 days. The solution obtained was filtered through Whatman no. 1 filter paper. The supernatant was dried at room temperature. The dry powder of the root extract was stored in air tight sterile bottle.

\section{Animals}

Female wistar rats, 7-8 weeks of age and 130-140 g weight were chosen for the current study. They were procured from central animal house of Sri Kaliswari college, Sivakasi, India. The rats were housed at room temperature and light-dark cycle of $12 \mathrm{hrs}$. They were allowed free access to standard pellet diet and water ad libitum. The study was initiated after clearance from Institutional animal ethics committee.

\section{Experiment}

The experimental protocol is summarized in Figure 1. 24 Wistar rats were divided into 4 groups randomly. Group 1 (control group) were administered distilled water (vehicle). DMBA (30mg/kg body weight, single dose) was injected intraperitoneally to group 2 rats on day 5 of the experiment.

Group 3 received pre-treatment with C. procera root extract $(500 \mathrm{mg} / \mathrm{kg}$ body weight) orally for 5 days. On day 5 , they were given DMBA injection $(30 \mathrm{mg} / \mathrm{kg}$ body weight) intraperitoneally $2 \mathrm{hrs}$ after the extract. Group 4 rats received only $C$. procera root extract $(500 \mathrm{mg} / \mathrm{kg}$ body weight) for 5 days per oral. They did not receive DMBA injection. All rats were fasted overnight and sacrificed on day 6 by cervical dislocation (Figure 1).

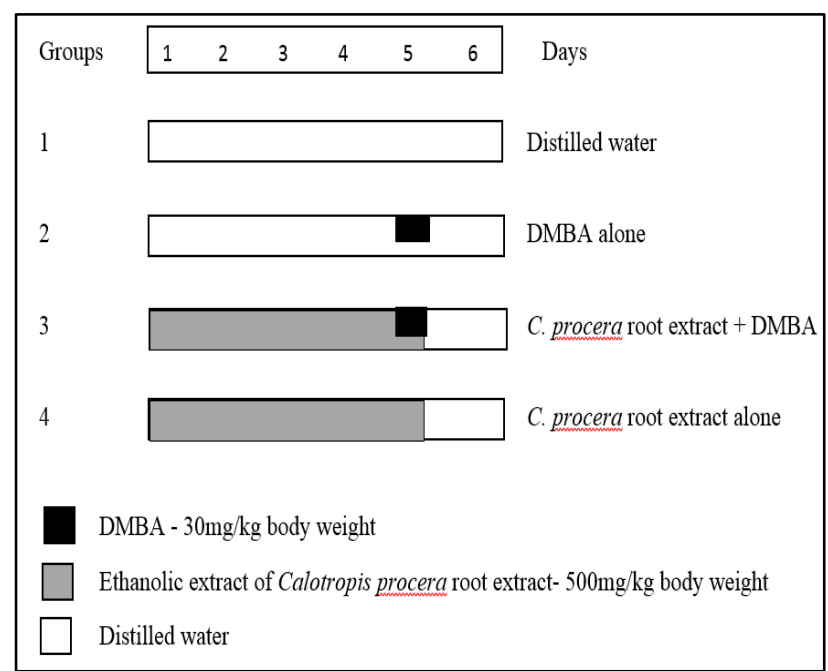

Figure 1: Experimental protocol for antioxidant study.

\section{Antioxidant activity}

It was assessed by measuring the levels of thiobarbituric acid reactive substance (TBARS) and enzymatic antioxidants in plasma and erythrocytes. Conjugated dienes levels were estimated in plasma.

\section{Estimation of TBARS}

\section{Plasma TBARS}

The procedure described by Yagi et al, was followed. ${ }^{19}$ Phosphotungstic acid was added to plasma for deproteinising it. Thiobarbituric acid was added at $90^{\circ} \mathrm{C}$ for 1 hour. The pink colour so formed was estimated at $530 \mathrm{~nm}$. This gives an estimation of TBARS. The values were presented as $\mathrm{nmol} / \mathrm{ml}$.

\section{Erythrocyte TBARS}

It was estimated as per the procedure described by Donnan et al. ${ }^{20}$ Erythrocytes were mixed with $10 \%$ trichloroacetic acid (TCA). The solution was filtered, and the filtrate was combined with thiobarbituric acid. The resultant chromogen was read at $535 \mathrm{~nm}$. The levels were presented as pmoles /mg $\mathrm{Hb}$.

\section{Conjugated dienes estimation}

They were assayed by the procedure of Rao et al. ${ }^{21}$ Plasma was mixed with chloroform-methanol reagent and centrifuged. Cyclohexane was added to the mixture and absorbance was estimated at $233 \mathrm{~nm}$. The concentration of dienes was measured in $\mu \mathrm{mol} / \mathrm{ml}$. 


\section{Estimation of enzymatic antioxidants}

\section{Superoxide dismutase (SOD)}

The procedure of Kakkar et al, was followed for the enzyme estimation. ${ }^{22}$ Sample was mixed with sodium pyrophosphate buffer, phenazine methosulfate and NBT. $\mathrm{NADH}$ was added and the mixture was incubated. Centrifugation was done after addition of glacial acetic acid and n-butanol. Chromogen was estimated at $560 \mathrm{~nm}$. The activity was expressed as $\mathrm{U} / \mathrm{ml}$ for plasma and $\mathrm{U} / \mathrm{mg}$ $\mathrm{Hb}$ for erythrocyte lysate.

\section{Catalase (CAT)}

It was assessed according to the procedure of Sinha et al. ${ }^{23}$ Sample was mixed with $\mathrm{H}_{2} \mathrm{O}_{2}$, phosphate buffer and dichromate acetic acid. The mixture was kept in boiling water bath. Colour developed was measured at $620 \mathrm{~nm}$. Values were presented as $\mathrm{U} / \mathrm{ml}$ for plasma and $\mathrm{U} / \mathrm{mg} \mathrm{Hb}$ for erythrocyte lysate.

\section{Glutathione peroxidase (GPx)}

GPx activity was measured by the method of Rotruck et al, with modifications. ${ }^{24}$ Sample was mixed with $\mathrm{H}_{2} \mathrm{O}_{2}$ and GSH. The remaining amount of GSH was allowed to react with DTNB. Yellow colour so formed was estimated at $412 \mathrm{~nm}$. Enzyme activity was represented as $\mathrm{U} / \mathrm{ml}$ for plasma and $\mathrm{U} / \mathrm{g} \mathrm{Hb}$ for erythrocyte lysate.

\section{Statistical analysis}

The data was expressed as mean \pm SD. Analysis of data was done using one-way ANOVA and Duncan's multiple range test. $\mathrm{P}<0.05$ was considered significant. Data analysis was done with Graph Pad prism version 6.05.

\section{RESULTS}

TBARS levels and antioxidant enzymes activities (SOD, CAT, GPx) were measured in plasma and erythrocytes. Conjugated dienes levels were estimated in plasma. TBARS and conjugated dienes formation was taken as an index of lipid peroxidation.

TBARS levels were expressed as $\mathrm{nmol} / \mathrm{ml}$ of plasma and pmoles/mg Hb in erythrocytes. The concentration of dienes was measured in $\mu \mathrm{mol} / \mathrm{ml}$. The SOD activity was expressed as $\mathrm{U} / \mathrm{ml}$ for plasma and $\mathrm{U} / \mathrm{mg} \mathrm{Hb}$ for erythrocyte lysate. CAT activity was represented as $\mathrm{U} / \mathrm{ml}$ for plasma and $\mathrm{U} / \mathrm{mg} \mathrm{Hb}$ for erythrocyte lysate. GPx activity was represented as $\mathrm{U} / \mathrm{ml}$ for plasma and $\mathrm{U} / \mathrm{g} \mathrm{Hb}$ for erythrocyte lysate.

The effect of ethanolic extract of Calotropis procera root on plasma TBARS, conjugated dienes and antioxidant enzymes levels in wistar rats are presented in Table 1.

DMBA treated rats (group 2) showed statistically significant increase in levels of TBARS and conjugated dienes and decrease in antioxidant enzymes activity compared to control group (Table 1).

Group 3 animals showed TBARS and conjugated dienes levels comparable to control animals. The antioxidant enzymes activities were also comparable to control group except GPx, whose activity was decreased statistically significantly (Table 1).

The TBARS and conjugated dienes levels and antioxidant enzymes activities in group 4 animals (C. procera alone) were comparable to control group (Table 1). The effect of Calotropis procera root extract on erythrocytes TBARS and antioxidant enzymes levels in wistar rats are presented in Table 2.

Table 1: Plasma TBARS, conjugated dienes and antioxidant enzymes levels in wistar rats.

\begin{tabular}{|llllll|} 
Treatment group & Plasma TBARS & Conjugated dienes & SOD & GPx & CAT \\
\hline Group 1- Distilled water (control) & $39 \pm 2.18$ & $22 \pm 0.96$ & $76 \pm 1.32$ & $187 \pm 2.3$ & $53 \pm 3.02$ \\
\hline Group 2- DMBA & $77 \pm 1.47^{* * *}$ & $58 \pm 2.6^{* * *}$ & $47 \pm 1.82^{* *}$ & $78 \pm 1.56^{* * *}$ & $19 \pm 2.1^{* * *}$ \\
\hline Group 3- DMBA + C. procera & $44 \pm 2.0$ & $31 \pm 2.3$ & $79 \pm 1.42$ & $119 \pm 2.1^{* * *}$ & $39 \pm 2.2$ \\
\hline Group 4- C. procera & $34 \pm 2.95$ & $28 \pm 1.9$ & $89 \pm 1.87$ & $179 \pm 1.92$ & $51 \pm 2.68$ \\
\hline
\end{tabular}

Data expressed as mean \pm SD. $\mathrm{n}=6 ;{ }^{*} \mathrm{p}<0.05,{ }^{* *} \mathrm{p}<0.01, * * * \mathrm{p}<0.001$ (compared with control)

Table 2: Erythrocyte TBARS and antioxidant enzymes levels in wistar rats.

\begin{tabular}{|lllll|}
\hline Treatment group & RBC TBARS & SOD & GPx & CAT \\
\hline Group 1- Distilled water (control) & $58 \pm 1.67$ & $45 \pm 1.97$ & $31 \pm 2.9$ & $73 \pm 2.87$ \\
\hline Group 2- DMBA & $86 \pm 1.27^{* * *}$ & $11 \pm 0.92^{* * *}$ & $9 \pm 0.98^{* *}$ & $30 \pm 1.97^{* * *}$ \\
\hline Group 3- DMBA + C. procera & $74 \pm 2.0^{*}$ & $29 \pm 1.52^{*}$ & $20 \pm 1.39^{*}$ & $67 \pm 2.1$ \\
\hline Group 4 - C. procera & $67 \pm 2.8$ & $43 \pm 1.89$ & $34 \pm 2.87$ & $71 \pm 2.15$ \\
\hline
\end{tabular}

Data expressed as mean \pm SD. $\mathrm{n}=6 ; * \mathrm{p}<0.05, * * \mathrm{p}<0.01, * * * \mathrm{p}<0.001$ (compared with control) 
Group 2 rats (DMBA alone) showed an increase in the TBARS levels and decrease in activities of antioxidant enzymes which were statistically significant compared to control group (Table 2). In group 3 rats, the TBARS levels were increased significantly and SOD and GPx activities were significantly decreased compared to control. CAT activity was comparable to control (Table 2). Group 4 ( $C$. procera alone) showed TBARS levels and antioxidant enzymes levels comparable to control (Table 2).

\section{DISCUSSION}

In current study, the antioxidant activity of ethanolic extract of Calotropis procera root was assessed in Wistar rats. Free radicals can cause lipid peroxidation, oxidation of proteins, damage to DNA, cell death. They are involved in the pathogenesis of various pathological conditions. ${ }^{25,26}$ Formation of TBARS and conjugated dienes is an indicator of free radical mediated lipid peroxidation. Concentration of lipid peroxides in plasma and tissues indicate the extent of tissue damage.

Endogenous antioxidants (enzymatic - SOD, CAT, GPx and non-enzymatic - vitamin C, E and GSH) scavenge the free radicals generated in the body. Insufficient antioxidant levels are an index of oxidative damage that persists within the cell. Decreased activities of antioxidant enzymes in plasma and erythrocytes are recognized in various malignancies, diabetes, inflammatory disorders etc. ${ }^{27}$ Glutathione peroxidase has regulatory influence on proliferation of cells. ${ }^{28}$ Increased glutathione peroxidase activity accounts for decreased oxidative stress. $^{29}$ Calotropis procera has been used in traditional medicine as an antioxidant. Hence the current study was undertaken to assess the antioxidant potential of ethanolic extract of Calotropis procera roots in wistar rats.

In present study, the levels of TBARS and conjugated dienes were significantly increased in DMBA treated rats (group 2) both in plasma and erythrocytes. Pretreatment with Calotropis procera root extract (group 3) has normalized the TBARS and conjugated dienes levels in plasma but in erythrocytes, the TBARS levels were elevated. Group 4 rats which received Calotropis procera extract alone showed TBARS and conjugated dienes levels comparable to control (group 1).

The activities of antioxidant enzymes (SOD, CAT, GPx) in plasma and erythrocytes were significantly decreased in group 2 rats treated with DMBA alone. In group 3 rats pretreated with $C$. procera root extract, GPx activity was significantly decreased in both plasma and erythrocytes and SOD activity was decreased in erythrocytes. CAT activity was comparable to control group. In group 4 rats (C. procera alone), the activities of antioxidant enzymes were comparable to control group.

The findings of present study are similar to the study of Kumar $S$ et al. who reported the antioxidant and membrane protective effects of $C$. procera root aqueous extract. ${ }^{30}$
Mohamed MA et al, also reported that Calotropis procera has in vitro antioxidant activity and cytotoxic activity in brine shrimp lethality bioassay. ${ }^{31}$ Murty Y et al, Bajpai S et al, Joshi $\mathrm{R}$ et al, also reported the antioxidant property of Calotropis procera. ${ }^{32-34}$

\section{CONCLUSION}

Based on the findings of our study, it can be concluded that ethanolic extract of Calotropis procera root exhibits antioxidant effect in wistar rats. However, further studies are required to elucidate the mechanism of this activity.

\section{ACKNOWLEDGEMENTS}

Authors would like to thank Dr. Kolanjiappan Kaliyaperumal for his guidance and Kavitha T. G. for her help and support.

\section{Funding: No funding sources}

Conflict of interest: None declared

Ethical approval: The study was approved by the Institutional Ethics Committee

\section{REFERENCES}

1. Parke DV, Sapota A. Chemical toxicity and reactive oxygen species. Int J Occcup Med Environmental Health. 1996;9(4):331-40.

2. Senthil N, Manoharan S. Lipid peroxidation and antioxidants status in patients with papillary thyroid carcinoma in India. Asia Pac J Clin Nutr. 2004;13 (4): 391-5.

3. Bandyopadhyay U, Das D, Banerjee RK. Reactive oxygen species: oxidative damage and pathogenesis. Current Sc. 1999 Sep 10:658-66.

4. Ames BN, Shigenaga MK, Hagen TM. Oxidants, antioxidants, and the degenerative diseases of aging. Proceedings National Acad Sci. 1993 Sep 1;90(17):7915-22.

5. Halliwell B. Free radicals, antioxidants, and human disease: curiosity, cause, or consequence?. Lancet. 1994 Sep 10;344(8924):721-4.

6. Yu BP. Cellular defenses against damage from reactive oxygen species. Physiological Rev. 1994 Jan 1;74(1):139-62.

7. Ahmad N, Anwar F, Hameed S and Boyce MC. Antioxidant and antimicrobial attributes of different solvent extracts from leaves and flowers of Calotropis procera. J Medicinal Plants Res, 2011;5(19):4879-87.

8. Chaudhary P, Ahamad S, Khan NA. A review on medicinal utility of Calotropis procera. WJPMR, 2017;3(1):335-42.

9. Parihar G, Balekar N. Immunomodulating potential of Calotropis procera (ait.) root bark ethanolic extract on experimental animal. J Adv Pharm Educ Res. 2014 Jul;4:268-76.

10. Sangraula H, Dewan S, Kumar VL. Evaluation of antiinflammatory activity of latex of Calotropis procera in 
different models of inflammation. Inflammopharmacol. 2001 Jun 1;9(3):257-64.

11. Roy S, Sehgal R, Padhy BM, Kumar VL. Antioxidant and protective effect of latex of Calotropis procera against alloxan-induced diabetes in rats. $\mathbf{J}$ Ethnopharmacol. 2005 Dec 1;102(3):470-3.

12. Basu A, Sen T, Pal S, Mascolo N, Capasso F, Nag AK. Studies on the antiulcer activity of the chloroform fraction of Calotropis procera Root extract. Phytother Res. 1996;11(2):163-5.

13. Quaquebeke VE, Simon G, Andre A, Dewelle J, Yazidi ME, Bruyneel F, et al. Identification of a novel cardenolide (2-oxovoruscharin) from Calotropis procera and the hemisynthesis of novel derivatives displaying potent in vitro antitumor activities and high in vivo tolerance: Structure-activity relationship analyses. J Med Chem. 2005;48:849-5.

14. Basu A, Chaudhari AK. Preliminary studies on the anti-inflammatory and analgesic activities of Calotropis procera root extract. J Ethnopharmacol. 1991;31:319-24.

15. Shrivastava A, Singh S, Singh S. Phytochemical Investigation of Different Plant Parts of Calotropis procera. Int J Sci Res Publications. 2013;3(8):1-4.

16. Pugalendhi P, Manoharan S, Panjamurthy K, Balakrishnan S, Nirmal MR. Antigenotoxic effect of genistein against 7, 12-dimethylbenz [a] anthracene induced genotoxicity in bone marrow cells of female Wistar rats. Pharmacological Reports. 2009 Mar 1;61(2):296-303.

17. Ray G, Husain SA. Oxidant, antioxidants and carcinogenesis. Indian J Exp Biol. 2002;40:1213-32.

18. Nagini S, Manoharan S. Biomonitoring the chemopreventive potential of plant products neem and turmeric in 4-nitroquinoline-1-oxide induced oral carcinogenesis. J Clin Biochem Nutr. 1997;23(1):3340 .

19. Yagi K. Lipid peroxides and human diseases. Chemistry Physics Lipids. 1987 Nov 1;45(2-4):33751.

20. Donnan SK. The thiobarbituric acid test applied to tissues from rats treated in various ways. J Biological Chemistry. 1950 Jan 1;182(1):415-20.

21. Rao KS, Recknagel RO. Early onset of lipoperoxidation in rat liver after carbon tetrachloride administration. Experimental Molecular Pathol. 1968 Oct 1;9(2):271-8.

22. Kakkar P, Das B, Viswanathan PN. A modified spectrophotometric assay of superoxide dismutase. Ind J Bio Chem Bio Phys. 1984;21:130-2.

23. Sinha K.A. Colorimetric assay of catalase Bio Chem. 1972;47:389-94.
24. Rotruck JT, Pope AL, Ganther HE, Swanson AB, Hafeman DG, Hoekstra W. Selenium: biochemical role as a component of glutathione peroxidase. Science. 1973 Feb 9;179(4073):588-90.

25. Liu JI, Wang X, Shigenaga MK, Yeo HC, Mori A, Ames BN. Immobilization stress causes oxidative damage to lipid, protein, and DNA in the brain of rats. FASEB J. 1996 Nov;10(13):1532-8.

26. Olivenza R, Moro MA, Lizasoain I, Lorenzo P, Fernández AP, Rodrigo J, et al. Chronic stress induces the expression of inducible nitric oxide synthase in rat brain cortex. J Neurochem. 2000 Feb 1;74(2):785-91.

27. Ibrahim W, Lee US, Yen HC, Clair DK, Chow CK. Antioxidant and oxidative status in tissues of manganese superoxide dismutase transgenic mice. Free Radical Biol Med. 2000 Feb 1;28(3):397-402.

28. Ito Y, Kajkenova O, Feuers RJ, Udupa KB, Desai VG, Epstein J, Hart RW, Lipschitz Det alA. Impaired glutathione peroxidase activity accounts for the agerelated accumulation of hydrogen peroxide in activated human neutrophils. J Gerontol Series a: Biol Sci Med Sci. 1998 May 1;53(3):M169-75.

29. Baskaran N, Manoharan S, Karthikeyan S, Prabhakar MM. Chemopreventive potential of coumarin in 7, 12dimethylbenz[a]anthracene induced hamster buccal pouch carcinogenesis. Asian Pac J Cancer Prev. 2012;13(10):5273-9.

30. Kumar S, Gupta A, Pandey AK. Calotropis procera root extract has the capability to combat free radical mediated damage. ISRN Pharmacol. 2013 Oct 9;2013.

31. Mohamed MA, Hamed MM, Ahmed WS, Abdou AM. Antioxidant and cytotoxic flavonols from Calotropis procera. J Natural Sci. 2011 Dec 1;66(11-12):547-54.

32. Murti Y, Yogi B, Pathak D. In-vitro antioxidant activity of column chromatographic elutes of different extracts of Calotropis procera (giant milkweed) leaves. J Pharm Res. 2011;4(10):3452-4.

33. Bajpai S, Hooda H, Singh RK and Mishra R. Comparative analysis of antioxidant properties of extracts of Calotropis procera with different antidiabetic drugs. Int J Herbal Med. 2018;6(2):104-9.

34. Joshi R, Sharma A, Jat BL. Analysis of antioxidant activity in extracts of Calotropis procera (Ait.) R. Br. J Applied Biosci. 2009;17:899-903.

Cite this article as: Dayana K, Manasa MR.

Antioxidant activity of ethanolic extract of Calotropis procera root in wistar rats. Int J Basic Clin Pharmacol 2018;7:2107-11. 